\title{
Recombinant Factor VIII Fc Fusion Protein (rFVIIIFc) in Real Life: One-Year Clinical and Economic Outcomes
}

\author{
Romain Giraud $^{1} \cdot$ Nicolas Delmotte $^{1} \cdot$ Sophie Gensollen ${ }^{1} \cdot$ Martine Roche $^{2} \cdot$ Céline Falaise $^{2} \cdot$ Hervé Chambost $^{2,3}$. \\ Manon Roche ${ }^{4,5}$ (D)
}

Accepted: 6 May 2021 / Published online: 25 June 2021

(c) The Author(s) 2021

\begin{abstract}
Background Recombinant factor VIII Fc fusion protein ( $\mathrm{rFVIIIFc)} \mathrm{is} \mathrm{the} \mathrm{first} \mathrm{extended} \mathrm{half-life} \mathrm{(EHL)} \mathrm{recombinant} \mathrm{clotting}$ factor with marketing authorization; it has been available in France since October 2016. However, data and literature about rFVIIIFc in clinical practice are scarce.

Objective We propose a 1-year clinical and economic outcome evaluation in patients with hemophilia A taking into consideration treatment adherence.

Patients and methods We reviewed the diaries of all patients treated with $\mathrm{FFVIIIFc}$ at Marseille Hemophilia Center for 1 year. All the data were related to the patients' infusion (i.e., annual number of infusions, weekly dose $/ \mathrm{kg}$, and annual consumption) and bleeding reports. The clotting factor costs were considered, whereas additional costs (e.g., infusion devices and nurse intervention) were neglected.

Results A total of 34 patients were evaluated. Their median age was 18 years $(\mathrm{IQR}=18)$. Treatment adherence was observed in $62 \%$ for FVIII and $66 \%$ for rFVIIIFc. The analysis revealed a negligible decrease in the annual clotting factor consumption following the switch $(-2 \%, p=0.7339)$. These data were combined with a significant reduction in the annual number of infusion $(-22.5 \%$, median $=138.5$, IQR $=65.8$ for FVIII; median $=105$, IQR $=24$ for rFVIIIFc, $p<0.0001)$ and bleeding $(-50 \%$, median $=5, \mathrm{IQR}=7.5$ for FVIII; median $=1$, IQR $=4$ for $\mathrm{rFVIIIFc}, p<0.0001)$. With regard to the cost, a decreasing trend was observed $(-8 \%, p=0.1300)$.

Conclusion The analysis in a real-life setting revealed that the input of switches toward rFVIIIFc in different treatment (age of patients and regimen) patterns seems to corroborate previous studies. The results suggest that switches have a beneficial effect in terms of efficacy, clotting factor consumption, and cost.
\end{abstract}

Manon Roche

manon.roche@ap-hm.fr

Pharmacie de la Conception, AP-HM, Marseille, France

2 Centre de Traitement de l'Hémophilie (CTH), AP-HM, Marseille, France

3 INSERM 1263, INRA 1260, C2VN, Aix Marseille Univ, Marseille, France

4 Service Central des Opérations Pharmaceutiques, AP-HM, Marseille, France

5 UMR CNRS 7273, Aix Marseille Univ, Marseille, France

\section{Key Points}

Treatment adherence was observed in $66 \%$ of patients taking rFVIIIFc.

The median annualized bleeding rate is significantly less with rFVIIIFc.

We observed a cost saving of 384,636 EUR per year for all patients. 


\section{Introduction}

Hemophilia A (HA) is a congenital X-linked bleeding disease related to coagulation factor VIII (FVIII) deficiency. In severe forms of HA (FVIII < $1 \%$ ), patients develop complications, such as chronic arthropathy, due to repeated joint and muscle bleeding episodes with subsequent pain and disability.

Currently, treatment for HA involves replacement of the FVIII defect with plasma derivatives (pd-) or recombinant (r-) FVIII concentrates. Regular repeated infusion of FVIII, so-called prophylaxis, is the gold standard regimen for patients with severe hemophilia [1].

In previous years, extended half-life (EHL) recombinant clotting factors have been approved for the treatment of patients with hemophilia. In addition, different technologies have been explored to improve the pharmacokinetic characteristics of these drugs to reduce the burden of infusions and musculoskeletal complications.

Among many EHL rFVIII products that have been evaluated in clinical trials, rFVIIIFc (Efmoroctocog alpha, Eloctate $^{\circledR}$ ) was the first one to be approved for the treatment of patients with HA, both for prophylaxis and for treatment for bleeding episodes [2-20]. This drug is the first representative of a new pharmacological class (EHL rFVIII), and pharmacokinetic studies on adults have demonstrated a 1.5-fold increase in half-life compared with full-length rFVIII [21-24]. The FVIII binding Fcdomain of immunoglobulin $\mathrm{G}$ (i.e., recombinant fusion of B-domain deleted recombinant FVIII and the dimeric constant region of $\operatorname{Ig} 1$ ) shows very favorable pharmacokinetics. In fact, EHL is the result of recycling by the neonatal Fc receptor (FcRn), a substantial contribution from renal excretion to total clearance and, for certain peptibodies, target-mediated drug disposition [17, 25-29]. According to clinical studies, this drug may improve treatment and reduce unit consumption, thus decreasing the costs related to the use of EHL clotting factor [27, 28, 30, 31]. A few studies in real-life settings [32-34], based on administration diaries, have been conducted since the employment of switches [34]. The lack of data with regard to EHL clotting factor encourages further evaluation in clinical practice.

This study aimed to analyze switches to rFVIIIFc according to clinical and economic outcomes for a 12-month period.

\section{Patients and Methods}

All patients treated with rFVIIIFc at the Marseille Hemophilia Center whose data were available during the considered period were included in this evaluation. The medical records of all patients who started Efmoroctocog alfa treatment between November 2016 and January 2018 were analyzed. Patients on prophylaxis pre-switching were also considered.

\subsection{Data Collection}

The inclusion criteria in this study were as follows: any patient with severe or moderate HA and patients who were treated with FVIII for at least 1 year before the switching of their treatment to $\mathrm{rFVIIIFc}$ for 1 year afterward. Data were collected using AXIGATE ${ }^{\circledR}$ (university center database) and were supplemented with medical records and paper diaries. A full history of the FVIII treatment (e.g., prophylactic regimen and type of clotting factor) was obtained for the 12 months prior to switching and the 12 months after switching. No calculation or estimation on the prescribed regimen has been realized. The data for each patient were obtained from their notebooks, which were collected by the physicians during their medical consultations and then digitalized to be added to the patients' files. From their notebooks, information such as the day of the infusion, the number of IUs, and whether it was a prophylactic or episodic infusion could be obtained. In the case of a curative infusion, patients are required to include details of the infusion (location of bleeding and cause of bleeding). Bleeding episodes were reported by the patients/parents according to their knowledge of the disease acquired during their consultations and educative sessions at the center. All events were written on the patients' notebooks with details on the location and circumstances of occurrence (trauma or not). All information related to infusions for prophylaxis and treatment for bleeding episodes were distinguished by the reports on patients: infusion before the prescribed regimen and characterized bleeding or high risk for bleeding (i.e., trauma for children).

The definition of adherence categories was adapted from the criterion of Liesbeth et al. [35]: adherent $=$ missing $<15 \%$ infusions and dose changes of $<10 \%$; sub-optimally adherent $=$ missing $15-25 \%$ infusions and dose changes of $<25 \%$; and non-adherent $=$ missing $>25 \%$ infusions and dose changes of $>25 \%$. We analyzed the data related to the doses and infusions of each patient; moreover, we categorized the patients into three groups according to the criteria of Liesbeth et al. All reasons related to the switch were also noted to improve the analysis. 


\subsection{Statistical Analysis}

The analysis for this report was conducted using descriptive statistical methods, such as the mean, median (med), percentage, and interquartile range (IQR). The statistical analysis was conducted using the GraphPad Prism 7.0 software to measure the mean, median (med), percentage, and interquartile range (IQR); Student's $t$ test and Wilcoxon's signed-rank test were also employed. Statistical significance was set to $p<0.05$. The clotting factor costs were considered, whereas the additional costs (e.g., infusion devices and nurse intervention) were ignored.

\section{Results}

\subsection{Patient Characteristics}

A total of 52 patients were included in this study. However, 15 patients were excluded for an insufficient period after the switch, two of them because of clinical trial inclusion before the switch and one because his regimen profile was on demand. None of these previously treated patients developed an inhibitor. Their median age was 18 years $(\mathrm{IQR}=18)$.

Finally, 34 patients were included and categorized into three groups: patients $<12$ years of age $(n=8)$, patients between 12 and 18 years of age $(n=10)$, and patients $>18$ years of age $(n=16)$. All patients presented with severe HA, except one who suffered from moderate HA with a basal level of FVIII of $1 \%$. All data related to patient characteristics are presented in Table 1.

Considering numerous marketed clotting factors, we had already analyzed the reasons for the switch among such clotting factors: to improve bleed control $(n=18)$, to improve treatment adherence $(n=7)$, and to reduce infusion frequency $(n=23)$ [36]. The most observed reason was to reduce the frequency of infusions. Some patients had several different reasons for switching treatment: two $(6 \%)$ switched for three reasons, ten (29\%) for two reasons, and 22 (65\%) for one reason.

\subsection{Treatment Adherence}

Treatment adherence was observed in 21 patients (62\%) for FVIII before the switch and 22 patients $(65 \%)$ for rFVIIIFc after the switch. Non-adherence was more characterized by dose change, and it was observed in five patients (15\%) for FVIII and three patients (9\%) for rFVIIIFc. The distributions among adherent, sub-adherent, and non-adherent patient categories appear to be the same. Four patients (12\%) demonstrated worsening adherence to rFVIIIFc, whereas seven patients $(21 \%)$ became adherent or sub-adherent after the switch. High levels of adherence were observed in patients $<12$ years of age and patients between 12 and 18 years, of whom only three and two patients presented sub-optimal adherence to FVIII and rFVIIIFc, respectively. Patients > 18 years had lower rates of adherence.

\subsection{Treatment Data}

The analysis revealed a slight decrease in clotting factor consumption following the switch $(-2 \%, p=$ NS 0.7339$)$, with a total utilization of 7,001,500 IU (med $=185,000, \mathrm{IQR}=$ 192,625) for FVIII and 6,892,500 IU (med $=202,000$, IQR $=159,000)$ for rFVIIIFc. This indicates an annual rFVIIIFc consumption of $2417 \mathrm{IU} \cdot \mathrm{kg}^{-1}(\mathrm{med}=67, \mathrm{IQR}=24)$.

The annual clotting factor consumption decreased negligibly by $2 \%$ ( $p=0.6191$ ) for prophylaxis but decreased
Table 1 Baseline characteristics of patients

\begin{tabular}{ll}
\hline Characteristic & \\
\hline Age (years) & Median $=18$ (IQR 18; range 4-77) \\
$<12$ & $N=8(24 \%)$ \\
$12-18$ & $N=10(29 \%)$ \\
$>18$ & $N=16(47 \%)$ \\
Severity level & \\
Severe & $33(97 \%)$ \\
Moderate & $1(3 \%)$ \\
Weight & Median $=66($ IQR 46.5; range 15-101) \\
History of inhibitor & $N=0(0 \%)$ \\
Previous treatment data ${ }^{a}$ & \\
Recombinant factor as previous treatment & $N=30(88 \%)$ \\
Plasma-derived factor concentrate as previous treatment & $N=6(17 \%)$ \\
Regimen & \\
Prophylaxis treatment & $N=34(100 \%)$ \\
\hline
\end{tabular}

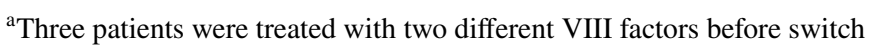


significantly by $50 \%(p<0.0001)$ for treatment for bleeding episodes.

Considering each pool of patients, 12- to 18-year-old patients demonstrated the highest decrease in clotting factor consumption $(-9 \%, p=0.0967)$. It should be noted that $24 \%$ of the patients were $<12$ years of age and that for $59 \%$ of the patients, the switch appeared as an opportunity to adjust the doses for weight evolution, clinical need, or ease of use.

These data were combined with a significant reduction in the annual number of infusion $(-23 \%$, med $=139, \mathrm{IQR}=66$ for FVIII; med $=105$, IQR $=24$ for rFVIIIFc, $p<0.0001$ ). These results revealed a more significant decrease in infusion frequency for episodic bleeding than for prophylaxis. In fact, the annual number of infusions with rFVIIIFc was reduced from 4492 to $3470(-23 \%, p<0.0001$ for prophylaxis and $-50 \%, p<0.0001$ for bleeding). This downward trend was observed in each patient group. In patients $<12$ years old, we observed a decrease in infusion frequency to treat bleeding episodes $(-46 \%, p=0.0625)$.

The median number of weekly infusions was three (IQR $=1)$ and two $(\mathrm{IQR}=0)$ for FVIII and rFVIIIFc, respectively.
A total of 19 patients (56\%) were concerned by a reduction of infusions. The frequency was decreased to once a week in five patients.

While the annual prophylaxis consumption of $\mathrm{rFVIIIFc}$ is equivalent to that of FVIII, the patients' quality of life is improved on a daily basis due to a significant decrease in prophylactic infusions. Furthermore, a better control of bleeding episodes with rFVIIIFc leads to a $50 \%$ decrease in episodic infusions, indicating a significant decrease in the total number of infusions throughout the year.

With regard to the dose, we noted the median weekly pre-switch dose and weekly post-switch dose of 73.02 IU $\mathrm{kg}^{-1}(\mathrm{IQR}=52.74)$ and $68.87 \mathrm{IU} \mathrm{kg}{ }^{-1}(\mathrm{IQR}=31.40)$, respectively, for FVIII and $\mathrm{rFVIIIFc}(-5 \%, p=0.2678)$. When we considered only prophylactic infusions, we noted a very stable median weekly pre-switch dose and weekly post-switch dose of $68.50 \mathrm{IU} \mathrm{kg}^{-1}$ (IQR = 40.84) and 67.47 IU kg-1 (IQR = 24.34), respectively, for FVIII and rFVIIIFc $(-3 \%, p=0.6980)$. No significant variation for each pool categorized by age was observed. It should be noted that the initial FVIII dose is different for each pool (from 46.75 to 92 $\mathrm{IU} \cdot \mathrm{kg}^{-1}$ for teenagers).

Table 2 Change in annual clotting factor consumption

\begin{tabular}{|c|c|c|c|}
\hline$N=34$ & FVIII & rFVIIIFc & $P$ \\
\hline \multicolumn{4}{|l|}{ Treatment } \\
\hline Annual consumption-IU.year ${ }^{-1}($ median $\pm \mathrm{IQR})$ & $(185,000 \pm 192,625)$ & $(202,000 \pm 159,000)$ & NS \\
\hline Annual consumption-prophylaxis IU.year ${ }^{-1}($ median $\pm \mathrm{IQR})$ & $(179,000 \pm 133,125)$ & $(193,750 \pm 141,000)$ & NS \\
\hline Annual consumption—bleeding episodes IU.year ${ }^{-1}($ median \pm IQR) & $(9500 \pm 18,000)$ & $(3000 \pm 7188)$ & 0.0002 \\
\hline Annual number of infusions-prophylaxis n per patient per year, (median $\pm I Q R$ ) & $(127 \pm 66)$ & $(101 \pm 22)$ & $<0.0001$ \\
\hline Annual number of infusions-bleeding episodes n per patient per year (median $\pm \mathrm{IQR}$ ) & $(8 \pm 11)$ & $(1 \pm 7)$ & $<0.0001$ \\
\hline Weekly dose IU kg ${ }^{-1}$ (median \pm IQR) & $(76 \pm 51)$ & $(69 \pm 28)$ & NS \\
\hline
\end{tabular}

$N S$ non-significant difference, $I Q R$ interquartile range

Table 3 Clinical criteria evolution-FVIII/rFVIIIFc

\begin{tabular}{|c|c|c|c|c|c|c|c|c|}
\hline \multirow[t]{2}{*}{ Treatment } & \multicolumn{2}{|l|}{ All patients } & \multicolumn{2}{|l|}{$<12$ years old } & \multicolumn{2}{|c|}{$12-18$ years old } & \multicolumn{2}{|l|}{$>18$ years old } \\
\hline & Evolution (\%) & $P$ & Evolution (\%) & $P$ & Evolution (\%) & $P$ & Evolution (\%) & $P$ \\
\hline Annual consumption—global & -2 & NS & +6 & NS & -9 & NS & +2 & NS \\
\hline Annual consumption-prophylaxis (\%) & +2 & NS & +10 & NS & -7 & NS & +7 & NS \\
\hline $\begin{array}{l}\text { Annual consumption-bleeding episodes } \\
(\%)\end{array}$ & -50 & 0.0008 & -39 & NS & -32 & NS & -67 & 0.0146 \\
\hline Number of infusions - Global & -23 & $<0.0001$ & -21 & 0.0391 & -28 & 0.002 & -18 & 0.003 \\
\hline Number of infusions-prophylaxis (\%) & -20 & $<0.0001$ & -22 & NS & -27 & 0.002 & -15 & 0.0115 \\
\hline $\begin{array}{l}\text { Number of infusions-bleeding episodes } \\
(\%)\end{array}$ & -52 & $<0.0001$ & -46 & NS & -41 & 0.0391 & -71 & 0.0176 \\
\hline Weekly dose (\%) & -5 & NS & -6 & NS & -12 & NS & +3 & NS \\
\hline
\end{tabular}

$N S$ non-significant difference

${ }^{\text {a}}$ Paired Student's $t$ test

${ }^{\mathrm{b}}$ Wilcoxon signed rank test 


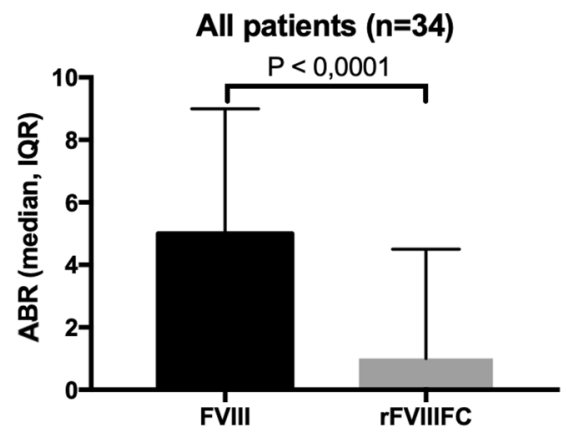

Significant decrease of bleeding episodes in all subgroups formed by age $\begin{array}{ll}\circ & -41 \% p=0.0312(<12 \text { years old; } \mathrm{n}=8) \\ \circ & -45 \% p=0.043(12-18 \text { years old; } \mathrm{n}=10) \\ \circ & -64 \% p=0.0020(>18 \text { years old; } \mathrm{n}=16)\end{array}$

Fig. 1 Change in annualized bleeding rate (ABR)

All the general data for weekly dose are presented in Table 2, and the data with regard to the pools are presented in Table 3.

\subsection{Clinical Outcomes}

In the efficacy assessment, 105 bleeding episodes occurred during the considered period with rFVIIIFc. Among these episodes, 32 occurred in patients aged $<12$ years, 49 in patients aged $12-18$ years, and 24 in patients aged $>18$ years. The median annualized bleeding rate (ABR) was $5(\mathrm{IQR}=7.5)$ for FVIII and $1(\mathrm{IQR}=4)$ for rFVIIIFc $(-50 \%, p<0.0001)$. The results are presented in Fig. 1 . rFVIIIFc may enhance treatment for the patients included in this study. The median results are presented in Table 4. Adult patients presented the most significant decrease in bleeding episodes after the switch. Bleeding changes after the switch are presented in Fig. 2.

One patient demonstrated an increased number of bleeding episodes for the considered period, and we noted a worsening adherence to rFVIIIFc (i.e., 78-71\%). The number of patients who did not bleed during the evaluation period increased from seven to 13 (i.e., 21-38\%).
Table 4 Clinical outcomes: Bleeding episodes

\begin{tabular}{|c|c|c|c|}
\hline$N=34$ & FVIII & rFVIIIFc & $P$ \\
\hline \multicolumn{4}{|l|}{ All patients } \\
\hline Bleeding episodes, $n$ year $^{-1}($ median $\pm \mathrm{IQR})$ & $(5,8)$ & $(1,4)$ & $<0.0001$ \\
\hline Subjects with no bleeding episode, $n(\%)$ & $7(20.6)$ & $13(38.2)$ & \\
\hline \multicolumn{4}{|l|}{$<12$ years old } \\
\hline Bleeding episodes, $n$ year $^{-1}($ median $\pm \mathrm{IQR})$ & $(7.5 \pm 4.5)$ & $(3 \pm 6)$ & 0.0312 \\
\hline \multicolumn{4}{|l|}{$12-18$ years old } \\
\hline Bleeding episodes, $n$ year $^{-1}($ median $\pm \mathrm{IQR})$ & $(6 \pm 7.5)$ & $(2 \pm 6)$ & 0.043 \\
\hline \multicolumn{4}{|l|}{$>18$ years old } \\
\hline Bleeding episodes, $n$ year $^{-1}($ median $\pm \mathrm{IQR})$ & $(1 \pm 5.5)$ & $(0 \pm 1)$ & 0.002 \\
\hline
\end{tabular}

$I Q R$ interquartile range
Fig. 2 Change in bleeding episodes after switching of patient treatment. Each icon (dot, square, or triangle) represents one patient. The first column represents all patients, then the three next columns show patients according to their age. y. old years old

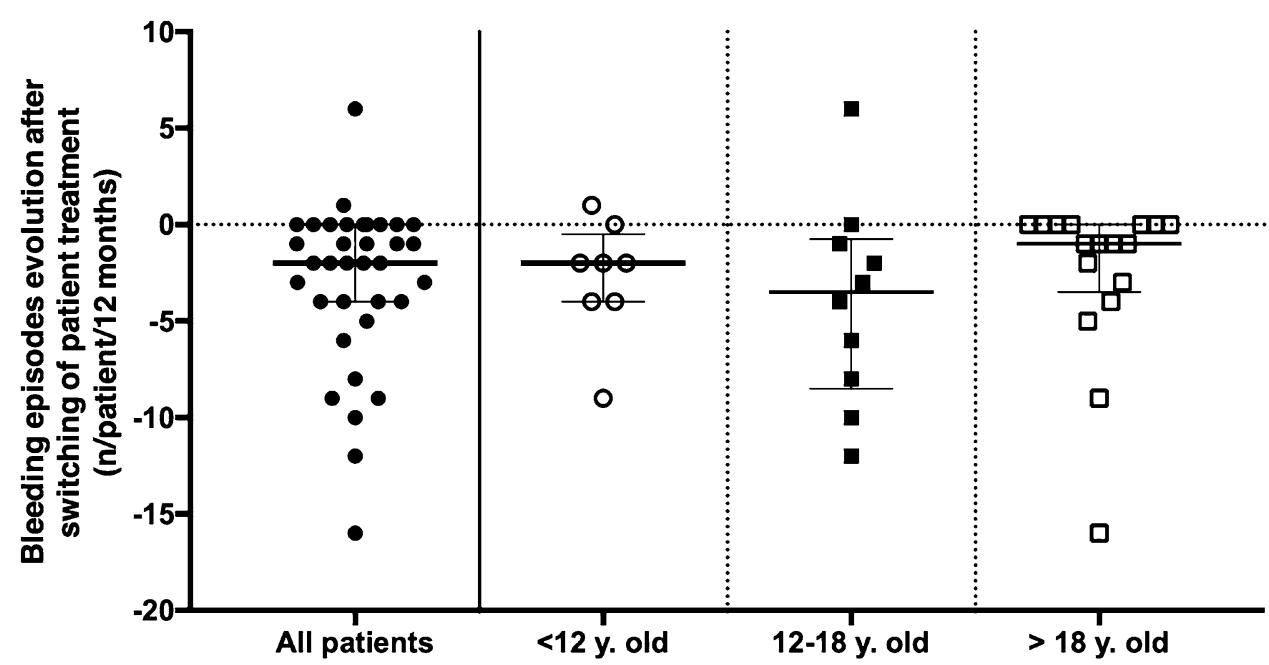




\subsection{Cost-of-Care Analysis}

The cost is $0.662 €$ per IU for conventional FVIII and rFVIIIFc in the national health insurance office. Globally, a negligible reduction in cost is described in this study $(-8 \%, p$ $=0.1300)$. We noted a median cost per patient per year of $132,876 €(\mathrm{IQR}=138,690 €)$ for FVIII and 141,228 $€($ IQR $=115,595 €)$ for $\mathrm{rFVIIIFc}$. A significant decrease in the cost of care was observed in 12 - to 18 -year-old patients $(-15 \%$, $p=0.0059)$. It is important to consider each pool of patients to analyze the cost savings.

All results are presented in Table 5.

\section{Discussion and Conclusion}

This study evaluated the real-life conditions of patients with severe hemophilia who were treated with FVIII during the first year and then with EHL FVIII (rFVIIIFc) subsequently. We explored the clinical and economic issues as well as the adherence criteria to complete our analysis. A decline in treatment adherence was observed in patients with hemophilia A (HA), particularly in adults. Such an adherence can lead to increased bleeding episodes and therefore clotting factors. Adherence presents a major issue considering the evaluation of clinical outcomes and treatment efficacy. EHL replacement therapy may influence the adherence and prophylactic regimen strategy [37-40]. Our results indicate that age may influence the change in adherence rate before and after the switch. These results may be discussed with an analysis of these data after a longer post-switch period [41, 42]. The incidence rate of acquiring new FVIII inhibitors in patients with severe HA is around 30\% [43]. In our study, no patients were found to acquire alloantibodies against exogenous FVIII before and after the switch during the reporting period.

Given the reasons for the switches, our results indicate that the goals were met for patients. All the patients remained on Efmoroctocog alfa (Eloctate ${ }^{\circledR}$ ) in our study (no switch-back). Our data were consistent with a real-life experience with pegylated FVIII [44].

The treatment data are related to a negligible decrease in the pre- and post-switch weekly median dose. It may be considered that in our population, the decrease in the weekly median dose is less important than it was in previous reports [31]. This point could be explained by the fact that our data were collected from patients' diaries for 1 year and were not a projection based on their initial prescribed dose over a period of 6 months.

Physicians' choice of the initial switch dose could be reevaluated later in terms of treatment adherence and clinical efficacy/number of bleeding episodes. In fact, patients who were switched to an increased initial dose experienced numerous bleeding episodes before the switch. Such an increased dose led to a significant decrease in bleeding episodes $(-75 \%, p=0.0020)$; this can be explained by the weight gain due to the normal growth of young patients.

One interesting thing about this real-life study is that clinical studies directed toward the evaluation of safety and efficacy of Efmoroctocog alfa $\left(\right.$ Eloctate $\left.^{\circledR}\right)$ did not consider the usual prophylactic regimen with regard to dose [45]. In clinical studies, the rFVIIIFc median weekly dose $\mathrm{kg}^{-1}$ range was from $65.4 \mathrm{IU} \cdot \mathrm{kg}^{-1}$ (A-LONG, modified prophylaxis group) to $99.9 \mathrm{IU} \cdot \mathrm{kg}^{-1}$ (Kids-A-LONG, subjects with individualized prophylaxis and $<6$ years old). Here, we described a median weekly dose of $68.87 \mathrm{IU} \cdot \mathrm{kg}^{-1}(\mathrm{IQR}=31.40)$, and when we considered only prophylactic regimen infusions, we observed a median weekly dose of $67.47 \mathrm{IU} \cdot \mathrm{kg}^{-1}$ (IQR $=24.34)$. The median weekly doses were $81.2 \mathrm{IU} \cdot \mathrm{kg}^{-1}$ $(\mathrm{IQR}=13.3)$ for patients $<12$ years old, $76 \mathrm{IU} \cdot \mathrm{kg}^{-1}(\mathrm{IQR}=$ $30.8)$ for teenagers, and $57.1 \mathrm{IU} \cdot \mathrm{kg}^{-1}(\mathrm{IQR}=16.0)$ for adult patients. Clinical evaluation and adjustment of doses related to each patient could be discussed. In fact, the medical reevaluation and efficacy analysis for the switch did not require an increase in the weekly dose as expected, considering the number of bleeding episodes before the switch.

Consistent with clinical studies, most of the patients presented low weekly infusion frequency (19 patients, 56\%).

Table 5 Cost-of-care analysis

\begin{tabular}{|c|c|c|c|c|}
\hline$N=34$ & FVIII & rFVIIIFc & Evolution (\%) & $P$ \\
\hline \multicolumn{5}{|l|}{ All patients } \\
\hline $\begin{array}{l}\text { Cost of care, } € \text { per year for all patients, (median } \pm I Q R) \\
<12 \text { years old }\end{array}$ & $(132,876 \pm 138,690)$ & $(141,228 \pm 115,595)$ & -8 & NS \\
\hline $\begin{array}{l}\text { Cost of care, } € \text { per year for all patients, (median } \pm \text { IQR) } \\
12-18 \text { years old }\end{array}$ & $(74,160 \pm 25,920)$ & $(60,543 \pm 14,275)$ & -8 & NS \\
\hline $\begin{array}{l}\text { Cost of care, } € \text { per year for all patients, }(\text { median } \pm I Q R) \\
>18 \text { years old }\end{array}$ & $(196,560 \pm 95,796)$ & $(148,914 \pm 110,446)$ & -15 & 0.0059 \\
\hline Cost of care, $€$ per year for all patients, (median $\pm \mathrm{IQR})$ & $(149,616 \pm 110,992)$ & $(172,902 \pm 69,264)$ & -3 & NS \\
\hline
\end{tabular}

$I Q R$ interquartile range 
The dose frequency was decreased to once a week for five patients. This point is related to the adherence and prophylactic regimen conduction changes. While one patient in the once-weekly prophylaxis regimen presented worse adherence, others presented improved adherence (two patients), and one presented an unchanged level of adherence. For these patients, the mean dose was $45.71 \mathrm{IU} \cdot \mathrm{kg}^{-1}$ (range 30.84-62.13). It should be noted that these values are lower than those of the ASPIRE study for A-LONG subjects (65.4 IU kg-1) [22].

Our findings corroborate the findings of clinical studies and describe a significant reduction of bleeding episodes $(-50 \%, p<0.0001)$. The bleeding results are surprisingly different from those of the ABR ASPIRE extension [22, 25, 26] when we considered the age of the patients (Table 5).

With regard to the costs of FVIII consumption, a cost saving of $384,638 €(7.6 \%)$ per year was observed. Cost savings are more important than the budget impact that has been previously discussed $[27,28]$. Considering patients who maintained the same IU consumption over 15 consecutive days ( $n=14$ ), seven patients maintained the same number of infusions and seven patients reduced it. The results indicate a significant cost reduction $(-12 \%$, FVIII med cost $=192,240$ $€, \mathrm{IQR}=137,367 € ; \mathrm{rFVIIIFc}$ med cost $=176,040 €, \mathrm{IQR}=$ $140,123 €, p=0.0001)$.

However, these cost savings will be less important in the future considering the unit cost of modification of the FVIII price in relation to other innovative treatments.

The decrease in infusion frequency and bleeding episode could be related to patients' improved quality of life. This study is a new real-life evaluation of the switching of rFVIIIFc products but should be continued since such a switch affected the quality of life of these patients. This evaluation is currently under analysis. $\mathrm{FFVIIIFc}$ might improve the management of HA, thanks to better bleeding control and a decrease in infusion frequency along with a slight cost saving. While results from this study were not conclusive, including more patients in future studies may show a better efficacy of rFVIIIFc.

\section{Declarations}

Funding The authors have no relevant affiliations or financial involvements with any organization or entity with a financial interest in or financial conflict with the subject matter or materials discussed in the manuscript. No assistance was enlisted during the writing of the manuscript.

Conflict of interest Manon Roche, Sophie Gensollen, Martine Roche, Nicolas Delmotte, and Romain Giraud declare that they have no conflicts of interest. Céline FALAISE has received speaker honorarium from Novonordsik ${ }^{\circledR}$ and fees for participation in review activities by Roche $^{\circledR}$, CSL Berhing ${ }^{\circledR}$, Pfizer $^{\circledR}$, and Swedish Orphan Biovitrum ${ }^{\circledR}$. Hervé Chambost received consulting fees or honoraria and payment for lectures including service on speaker bureaus from Bayer ${ }^{\circledR}$,
Biomarin $^{\circledR}$, CSL Berhing ${ }^{\circledR}$, NovoNordisk ${ }^{\circledR}$, Pfizer $^{\circledR}$, Roche Chugai ${ }^{\circledR}$, and $\mathrm{SOBI}^{\circledR}$. None of the authors have any conflicts of interest that are directly relevant to the content of this article.

Ethical approval This study was approved by the institutional research ethics board, AP-HM, (no. 2019_12).

Consent to participate and consent for publication Consent to participate and Consent for publication are related to the institutional research ethics board authorization.

Availability of data and material The datasets generated during the current study are available from the corresponding author on reasonable request

Code software availability Prism Free Trial—GraphPad.

Author contributions All authors gave final approval of the version to be submitted and any revised version. ND made substantial contributions to conception and design, acquisition of data, and analysis of data. He participated in revising publication critically for important intellectual content. CF participated in revising it critically for important intellectual content. SG made substantial contributions to conception and design, acquisition of data, and the analysis of data. She participated in revising publication critically for important intellectual content. RG made substantial contributions to conception and design, acquisition of data, and analysis of data. He participated in revising publication critically for important intellectual content. HC made substantial contributions to conception and design, acquisition of data, the analysis of data. He participated in revising publication critically for important intellectual content. MR made substantial contributions to conception and design, the acquisition of data, the analysis and interpretation of data. She wrote the paper and participated in revising publication critically for important intellectual content. MR made substantial contributions to acquisition of data.

Open Access This article is licensed under a Creative Commons Attribution-NonCommercial 4.0 International License, which permits any non-commercial use, sharing, adaptation, distribution and reproduction in any medium or format, as long as you give appropriate credit to the original author(s) and the source, provide a link to the Creative Commons licence, and indicate if changes were made. The images or other third party material in this article are included in the article's Creative Commons licence, unless indicated otherwise in a credit line to the material. If material is not included in the article's Creative Commons licence and your intended use is not permitted by statutory regulation or exceeds the permitted use, you will need to obtain permission directly from the copyright holder. To view a copy of this licence, visit http://creativecommons.org/licenses/by-nc/4.0/.

\section{References}

1. Fischer K, Astermark J, Van Der Bom JG, Ljung R, Berntorp E, Gnobbee DE, van den Berg HM. Prophylaxis treatment for severe haemophilia: comparison of an intermediate-dose to a high-dose regimen. Haemophilia. 2002;38:753-60.

2. Lambert T, Benson G, Dolan G, Hermans C, Jiménez-Yuste V, Ljung R, Morfini M, Zupančić-Šalek S, Santagostino E. Practical aspects of extended half-life products for the treatment of haemophilia. Ther Adv Hematol. 2018;9(9):295-308.

3. Ljung RCR. Prevention and management of bleeding episodes in children with hemophilia. Paediatr Drugs. 2018;20(5):455-64. 
4. Morfini M, Gherardini S. Pharmacokinetic-based prediction of real-life dosing of extended half-life clotting factor concentrates on hemophilia. Ther Adv Hematol. 2018;9(6):149-62.

5. Pipe SW. Bioengineered molecules for the management of haemophilia: promise and remaining challenges. Haemophilia. 2018;24(Suppl 6):68-75.

6. Raso S, Hermans C. Recombinant factor VIII: past, present and future of treatment of hemophilia A. Drugs Today (Barc). 2018;54(4):269-81.

7. Van den Bossche D, Peerlinck K, Jacquemin M. New challenges and best practices for the laboratory monitoring of factor VIII and factor IX replacement. Int J Lab Hematol. 2018;40(Suppl 1):21-9.

8. Hermans C, Mahlangu J, Booth J, Schütz H, Santagostino E, Young G, Lee HY, Steinitz-Trost KN, Blanchette V, Berntorp E. Pharmacokinetic modelling and validation of the half-life extension needed to reduce the burden of infusions compared with standard factor VIII. Haemophilia. 2018;24(3):376-84.

9. Mahlangu J, Young G, Hermans C, Blanchette V, Berntorp E, Santagostino E. Defining extended half-life FVIII-A critical review of the evidence. Haemophilia. 2018;24(3):348-58.

10. Morfini M. Innovative approach for improved FVIII concentrate. Eur J Haematol. 2014;93:361-8.

11. Mei B, Pan C, Jiang H, Tjandra H, Strauss J, Chen Y, Liu T, Zhang X, Severs J, Newgren J, Chen J, Gu JM, Subramanyam B, Fournel MA, Pierce GF, Murphy JE. Rational design of a fully active, long-acting PEGylated factor VIII for hemophilia A treatment. Blood. 2010;116:270-9.

12. Ostergaard H, Bjelke JR, Hansen L, Petersen LC, Pedersen AA, Elm T, Moller F, Hermit MB, Holm PK, Krogh TN, Petersen JM, Ezban M, Sorensen BB, Andersen MD, Agerso H, Ahmadian H, Balling KW, Christiansen MLS, Knobe K, Nichols TC, Bjorn SE, Tranholm M. Prolonged half-life and preserved enzymatic properties of factor IX selectively PEGylated on native N-glycans in the activation peptide. Blood. 2011;118:2333-41.

13. Tiede A, Brand B, Fischer R, Kavakli K, Lentz SR, Rea C, Knobe $\mathrm{K}$, Viuff D. Enhancing the pharmacokinetic properties of recombinant factor VIII: first-in-man trial of glycoPEGylated recombinant factor VIII in patients with hemophilia A. J Thromb Haemost. 2013;11:670-8.

14. Coyle TE, Reding MT, Lin JC, Michaels LA, Shah A, Powell J. Phase I study of BAY 94-9027, a PEGylated B-domain-deleted recombinant factor VIII with an extended half-life, in subjects with hemophilia A. J Thromb Haemost. 2014;12:488-96.

15. Collins PW, Young G, Knobe K, Karim FA, Angchaisuksiri P, Banner C, Gürsel T, Mahlangu J, Matsushita T, Mauser-Bunschoten E, Oldenburg J, Walsh CE, Negrier C, Paradigm 2 Investigators. Recombinant long-acting glycoPEGylated factor IX in hemophilia B: a multinational randomized phase 3 trial. Blood. 2014;124:3880-6.

16. Collins PW, Moss J, Knobe K, Groth A, Colberg T, Watson E. Population pharmacokinetic modeling for dose setting of nonacog beta pegol (N9-GP), a glycoPEGylated recombinant factor IX. J Thromb Haemost. 2012;10:2305-12.

17. Mahlangu J, Powell JS, Ragni MV, Chowdary P, Josephson NC, Pabinger I, Hanabusa H, Gupta N, Kulkarni R, Fogarty P, Perry D, Shapiro A, Pasi KJ, Apte S, Nestorov I, Jiang H, Li S, Neelakantan S, Cristiano LM, Goyal J, Sommer JM, Dumont JA, Dodd N, Nugent K, Vigliani G, Luk A, Brennan A, Pierce GF, A-LONG Investigators. Phase 3 study of recombinant factor VIII Fc fusion protein in severe hemophilia A. Blood. 2014;123:317-25.

18. Powell JS, Pasi KJ, Ragni MV, Ragni MV, Ozelo MC, Valentino LA, Mahlangu JN, Josephson NC, Perry D, Manco-Johnson MJ, Apte S, Baker RI, Chan G, Novitzki N, Wong R, Krassova S, Allen G, Jiang H, Innes A, Li S, Cristiano LM, Goyal J, Sommer JM, Dumont JA, Nugent K, Vigliani G, Brennan A, Luk A, Pierce GF, B-LONG Investigators. Phase 3 study of recombinant factor IX Fc fusion protein in hemophilia B. N Engl J Med. 2013;369:2313-23.

19. Santagostino E, Negrier C, Klamroth R, Tiede A, Pabinger-Fasching I, Voigt C, Jacobs I, Morfini M. Safety and pharmacokinetics of a novel recombinant fusion protein linking coagulation factor IX with albumin (rIX-FP) in hemophilia B patients. Blood. 2012;120:2405-11.

20. Martinowitz U, Lissitchkov T, Lubetsky A, Jotov G, BarazaniBrutman T, Voigt C, Jacobs I, Wuerfel T, Santagostino E. Results of a phase I/II open-label, safety and efficacy trial of coagulation factor IX (recombinant), albumin fusion protein in haemophilia B patients. Haemophilia. 2015;21:784-90.

21. Nestorov I, Neelakantan S, Ludden TM, Li S, Jiang H, Rogge M. Population pharmacokinetics of recombinant factor VIII Fc fusion protein. Clin Pharmacol Drug Dev. 2015;4(3):163-74.

22. Nolan B, Mahlangu J, Perry D, Young G, Liesner R, Konkle B, Rangarajan S, Brown S, Hanabusa H, Pasi KJ, Pabinger I, Jackson S, Cristiano LM, Li X, Pierce GF, Allen G. Long-term safety and efficacy of recombinant factor VIII Fc fusion protein (FVIIIFc) in subjects with haemophilia A. Haemophilia. 2016;22(1):72-80.

23. George LA, Camire RM. Profile of efraloctocog alfa and its potential in the treatment of hemophilia A. J Blood Med. 2015;6:131-41.

24. Young G, Mahlangu J, Kulkarni R, Nolan B, Liesner R, Pasi J, Barnes C, Neelakantan S, Gambino G, Cristiano LM, Pierce GF, Allen G. Recombinant factor VIII Fc fusion protein for the prevention and treatment of bleeding in children with severe hemophilia A. J Thromb Haemost. 2015;13(6):967-77.

25. Frampton JE. Efmoroctocog alpha alfa: a review in haemophilia A. Drugs. 2016;76(13):1281-91.

26. Tiede A. Half-life extended factor VIII for the treatment of hemophilia A. J Thromb Haemost. 2015;13(Suppl 1):S176-9.

27. Lorenzoni V, Triulzi I, Turchetti G. Budget impact analysis of the use of extended half-life recombinant factor VIII (efmoroctocog alpha alfa) for the treatment of congenital haemophilia a: the Italian National Health System perspective. BMC Health Serv Res. 2018;18(1):596.

28. Institute for Quality and Efficiency in Health Care. Efmoroctocog alpha Alfa-Benefit Assessment According to § 35a Social Code Book V [Internet]. Cologne, Germany: Institute for Quality and Efficiency in Health Care (IQWiG); 2016. http://www.ncbi.nlm. nih.gov/books/NBK458421/. Accessed 20 Feb 2020.

29. Meißner T. Extended protection with efmoroctocog alpha alfa. MMW Fortschr Med. 2016;158(12):74.

30. Henry N, Jovanović J, Schlueter M, Kritikou P, Wilson K, Myrén KJ. Cost-utility analysis of life-long rophylaxis with recombinant factor VIIIFc vs recombinant factor VIII for the management of severe hemophilia A in Sweden. JMed Econ. 2018;21(4):318-25.

31. Keepanasseril A, Stoffman J, Bouskill V, Carcao M, Iorio A, Jackson S, Association of Hemophilia Centre Directors of Canada (AHCDC). Switching to extended half-life products in Canadapreliminary data. Haemophilia. 2017;23(4):365-7.

32. Carcao M, Zunino L, Young NL, Dover S, Bouskill V, Hilliard $\mathrm{P}$, Price VE, Blanchette VS. Measuring the impact of changing from standard half-life (SHL) to extended half-life (EHL) FVIII prophylaxis on health-related quality of life (HRQoL) in boys with moderate/severe haemophilia A: lessons learned with the CHOKLAT tool. Haemoph Off J World Fed Hemoph. 2020;26(1):73-8.

33. Croteau SE, Cheng D, Cohen AJ, Holmes CE, Malec LM, Silvey M, Thornburg CD, Wheeler AP, Kouides PA, Raffini LJ, Neufeld EJ. Regional variation and cost implications of prescribed extended half-life factor concentrates among U.S. Haemophilia Treatment Centres for patients with moderate and severe haemophilia. Haemophilia. 2019;25:668-75.

34. Peyvandi F, Garagiola I, Boscarino M, Ryan A, Hermans C, Makris M. Real-life experience in switching to new extended 
half-life products at European haemophila centres. Haemophilia. 2019;00:1-7.

35. Schrijvers LH, van der Zande MB, Peters M, Lock J, Cnossen MH, Schuurmans MJ, Fischer K. Adherence to prophylaxis and bleeding outcome in haemophilia: a multicentre study. Br J Haematol. 2016;174:454-60.

36. Fischer K, Konkle B, Broderick C, Kessler CM. Prophylaxis in real life scenarios. Haemophilia. 2014;20(4):106-13.

37. Bosworth H. Treatment adherence: concepts, interventions, and measurement. 1st ed. London: Psychology Press; 2006.

38. Haynes RB, Sackett DL, Gibson ES, Taylor DW, Hackett DW, Roberts RS, Johnson AL. Improvement of medication compliance in uncontrolled hypertension. Lancet. 1976;1(7972):1265-8.

39. Psaty BM, Koepsell TD, Wagner EH, Logerfo JP, Inui TS. The relative risk of incident coronary heart disease associated with recently stopping the use of beta-blockers. JAMA. 1990;263(12):1653-7.

40. Osterberg L, Blaschke T. Adherence to medication. N Engl J Med. 2005;353(5):487-97.
41. Resseguier N, Rosso-Delsemme N, Beltran A, et al. Determinants of adherence and consequences of the transition from adolescence to adulthood among young people with severe haemophilia (TRANSHEMO): study protocol for a multicentric French national observational crosssectional study. BMJ Open. 2018;8:022409.

42. Young G. From boy to man: recommendations for the transition process in haemophilia. Haemophilia. 2012;18(5):27-32.

43. Lusher JM, Arkin S, Abildgaard CF, Schwartz RS. Recombinant factor VIII for the treatment of previously untreated patients with hemophilia A. Safety, efficacy, and development of inhibitors. Kogenate Previously Untreated Patient Study Group. N Engl J Med. 1993;328(7):453-9.

44. Dunn AL, Ahuja SP, Mullins ES. Real-world experience with use of Antihemophilic Factor (Recombinant), PEGylated for prophylaxis in severe haemophilia A. Haemophilia. 2018;24:84-92.

45. Transparency committee opinion. https://www.has-sante.fr/ upload/docs/evamed/CT-14817_ELOCTA_PIC_INS_Avis2_ CT14817.pdf. 2016. Consulted 20-02-2020. 